\title{
ニオブとタンタルの液液抽出に おけるチタンの挙動についで
}

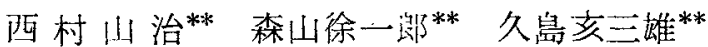

Sanji Nishimura, Joichiro Moriyama and Isao Kushima: Behavior of $\mathrm{Ti}$ in Liquid-Liquid Extraction of $\mathrm{Nb}$ and $\mathrm{Ta}$. The behavior of $\mathrm{Ti}$ in liquid-liquid solvent extraction of $\mathrm{Ta}$ and $\mathrm{Nb}$ using the organic solvent hexone was investigated in the four systems, namely, $\mathrm{HF}$-hexone, $\mathrm{HF}-\mathrm{HCl}$-hexone, $\mathrm{HF}-\mathrm{H}_{2} \mathrm{SO}_{4}$-hexone, and $\mathrm{HF}$ - $\mathrm{HNO}_{3}$-hexone. The results obtained can be summarized as follows: (1) By individually measuring the distribution coefficients of $\mathrm{Ti}$, Ta, and $\mathrm{Nb}$ in the extracting systems, it was found that $\mathrm{Ti}$ can be separated sufficiently from $\mathrm{Nb}$ and Ta. (2) The extractability of $\mathrm{Ti}$ rose with a rise of mineral-acid concentration at constant $\mathrm{HF}$ acidity, and particularly sharply from $4.5 \mathrm{~N} \mathrm{HCl}$ in $\mathrm{HF}-\mathrm{HCl}$-hexone system and from $10.6 \mathrm{~N} \mathrm{H}_{2} \mathrm{SO}_{4}$ in $\mathrm{HF}_{-} \mathrm{H}_{2} \mathrm{SO}_{4}$-hexone system, but more gradually with rise of $\mathrm{HNO}_{3}$ concentration or $\mathrm{HF}$ concentration in $\mathrm{HF}_{-} \mathrm{HNO}_{3}$-hexone and $\mathrm{HF}$-hexone systems. (3) In the limits of $\mathrm{HF}$ concentration investigated, the extractability of $\mathrm{Ti}$ lowered in the following order: In $\mathrm{HF}-\mathrm{HCl}$ system $>$ in $\mathrm{HF}-\mathrm{H}_{2} \mathrm{SO}_{4}$ systent $>$ in $\mathrm{HF}-\mathrm{HNO}_{3}$ system. (d) The cumulative $\mathrm{Ti} \%$ in organic extract increased with repetition of extraction operation in $\mathrm{HF}-\mathrm{HCl}, \mathrm{HF}-\mathrm{H}_{2} \mathrm{SO}_{4}$ and $\mathrm{HF}-\mathrm{HNO}_{3}$. In $\mathrm{HF}-\mathrm{H}_{2} \mathrm{SO}_{4}$ and $\mathrm{HF}-\mathrm{HNO}_{3}$ the weight of $\mathrm{Ti}$ extracted in the second extraction, showed the maximum, whereas in $\mathrm{HF}-\mathrm{HCl}$ system the fourth extraction produced the highest weight of extracted $\mathrm{Ti}$. (5) In general, the extractability of $\mathrm{Ti}$ in $\mathrm{HF}$-hexone system was smaller than in the other $\mathrm{HF}$-mineral acid-hexone systems, but in $\mathrm{HF}-\mathrm{H}_{2} \mathrm{SO}_{4}$ below $1.5 \mathrm{NH}_{2} \mathrm{SO}_{4}, \mathrm{HF}-\mathrm{HNO}_{3}$ below $4.2 \mathrm{NHNO}_{3}$ and in $\mathrm{HF}-\mathrm{HCl}$ below $0.8 \mathrm{~N} \mathrm{HCl}$, in which the $\mathrm{HF}$ acidity was $12.75 \mathrm{~N}$, Ti was less extractable than in $12.75 \mathrm{NHF}$-hexone system, and the coextraction efficiency of $\mathrm{Ta}$ and $\mathrm{Nb}$ was also larger than in the latter.

(Received September 13,1960)

\section{I. 緒}

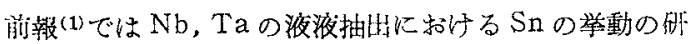

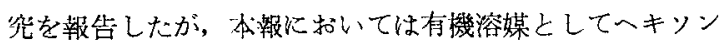

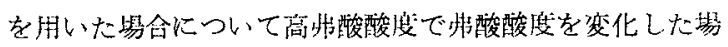
合一定の高弗酸酸度にて硫酸, 塩酸, 硝酸酸度を变化した 塄合抽出回数を変化した場合なぞについていキソン中に抽 出された $\mathrm{Nb}, \mathrm{Ta}$ 抽出物中の随伴不純物として, とくに Ti定量し, Ti 元素の挙動を抽出物中の含有率,含有量， 分配係数などについて検討した結果を報告する。

\section{II. 実験方 法}

実験 $\mathrm{A}$ に扎いて特級倵薬の $\mathrm{TiO}_{2}$ 省 $\mathrm{SnO}_{2}$ の代りに使朋 した以外は前解の実駼方法と全く同㥞に実駼を行い，抽出 物之抽残物枃熱科量し抽出物中の Ti 定毞分析した。 実験に使用した $\mathrm{Nb}_{2} \mathrm{O}_{5}, \mathrm{Ta}_{2} \mathrm{O}_{5}$ ，タンタライト精鉣の分析 倠はTable 1 に示される。

\section{III. 実 験 結 果}

1. 実験 A：一 - Ti，TaおよびNbの分配係数と分 離効率におよほす弗酸酸度および 硫酸酸度の影響

** 京都大学工学部治会学教室

*1960年4月本会東京大会に発表; ニオブとタンタル

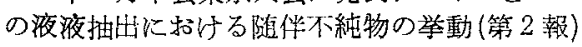

(1) 西村, 森山, 久島：本訟，24(1960),798

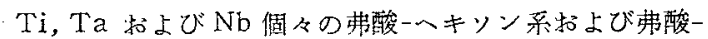
硫酸一キキンン系比怙ける抽出実騟を行い, 分配係数の測

Table 1 Chemical composition of $\mathrm{Ta}_{2} \mathrm{O}_{5}, \mathrm{Nb}_{2} \mathrm{O}_{5}$, and Tantalate concentrate. (wt $\%$ )

\begin{tabular}{|c|c|c|c|c|c|c|c|}
\hline & $\mathrm{Ta}_{2} \mathrm{O}_{5}$ & $\mathrm{Nb}_{2} \mathrm{O}_{5}$ & $\mathrm{FeO}$ & $\mathrm{TiO}_{2}$ & $\mid \mathrm{SnO}_{2}$ & $\mathrm{SiO}_{2}$ & $\mathrm{Mn}$ \\
\hline $\begin{array}{l}\mathrm{Ta}_{2} \mathrm{O}_{5} \\
\mathrm{Nb}_{2} \mathrm{O}_{5}\end{array}$ & $=99.8$ & $\begin{array}{c}0.05 \\
>99.8\end{array}$ & $\begin{array}{l}0.003 \\
0.005\end{array}$ & & & & \\
\hline $\begin{array}{l}\text { Hermann } \\
\text { Starck Ta } \mathrm{O}_{5}\end{array}$ & $>99.5$ & 0.1 & 0.005 & 0.05 & 0.1 & 0.1 & - \\
\hline $\begin{array}{c}\text { Tantalite } \\
\text { concentrate }\end{array}$ & 60.69 & 13.78 & 11.62 & 3.22 & 3.16 & 0.68 & 3.24 \\
\hline
\end{tabular}

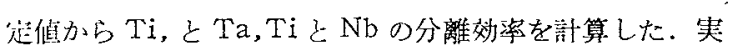
駼結柴は Table 2, Table 3 亿示す。供試水溶液中の $\mathrm{TiO}_{2}$

Table 2 Distribution coefficient and separation factor in $12.75 \mathrm{NHF}-\mathrm{H}_{2} \mathrm{SO}_{4}$-hexone system.

\begin{tabular}{c|c|r|r|r|r}
\hline \hline $\begin{array}{c}\mathrm{H}_{2} \mathrm{SO}_{4} \\
\text { Normality }\end{array}$ & \multicolumn{2}{|c|}{ Distribution coefficient } & \multicolumn{2}{|c|}{$\begin{array}{c}\text { Separation } \\
\text { factor }\end{array}$} \\
\hline & $K_{\mathrm{Ti}}$ & \multicolumn{1}{|c|}{$K_{\mathrm{Ta}}$} & $K_{\mathrm{Nb}}$ & $\beta_{\mathrm{Ta} / \mathrm{Ti}}$ & $\beta_{\mathrm{Nb} / \mathrm{Ti}}$ \\
\hline 11.35 & $1.06 \times 10^{-1}$ & 46.61 & 42.4 & 440 & 400 \\
7.08 & $2.48 \times 10^{-2}$ & 29.30 & 28.2 & 1181 & 1137 \\
4.25 & $9.91 \times 10^{-3}$ & 16.04 & 8.4 & 1619 & 848 \\
1.42 & $7.31 \times 10^{-3}$ & 3.50 & 1.17 & 480 & 160 \\
\hline
\end{tabular}

含有量は $7 \mathrm{~g} / \mathrm{L}, \mathrm{Ta}_{2} \mathrm{O}_{5}$ 含有輩忙 $72 \mathrm{~g} / \mathrm{L}, \mathrm{Nb}_{2} \mathrm{O}_{5}$ 含有量 $\Delta 0 \mathrm{~g} / \mathrm{L}$ であつた.

一定の高弗酸酸度 $12.75 \mathrm{~N}$ に和いては硫酸酸度の增加之 其炕 $\mathrm{Ti}, \mathrm{Ta}, \mathrm{Nb}$ の各分配係数 $\left(K_{\mathrm{Ti}}, K_{\mathrm{Ta}}, K_{\mathrm{Nb}}\right)$ はいずれ 
あ增大し， $K_{\mathrm{Ti}}$ は $K_{\mathrm{Ta}}$ と $K_{\mathrm{Nb}}$ に比べて粫めて小さいが， Fletcher $の 10 \mathrm{NHF}-1.2 \mathrm{NH}_{2} \mathrm{SO}_{4}$ - T.B.P 系の笑歌侹(2)

Table 3 Distribution coefficient and separation factor in $\mathrm{HF}$-hexone system.

\begin{tabular}{c|c|c|c|c|c}
\hline \hline \multirow{2}{*}{$\begin{array}{c}\mathrm{HF} \\
\text { Normality }\end{array}$} & \multicolumn{2}{|c|}{ Distribution coefficient } & \multicolumn{2}{c}{$\begin{array}{c}\text { Separation } \\
\text { factor }\end{array}$} \\
& $K_{\mathrm{Ti}}$ & $K_{\mathrm{Ta}}$ & $K_{\mathrm{Nb}}$ & $\beta_{\mathrm{Ta} / \mathrm{Ti}}$ & $\beta_{\mathrm{Nb} / \mathrm{T}}$ \\
\hline 21.2 & $2.03 \times 10^{-2}$ & 1.62 & 1.45 & 80 & 71 \\
15.9 & $1.00 \times 10^{-2}$ & 1.44 & $5.6 \times 10^{-1}$ & 104 & 56 \\
10.6 & $4.6 \times 10^{-3}$ & 1.19 & $1.7 \times 10^{-1}$ & 259 & 37 \\
7.95 & $3.0 \times 10^{-3}$ & 1.05 & $8.2 \times 10^{-2}$ & 350 & 27 \\
\hline
\end{tabular}

$K_{\mathrm{Ti}}=0.02$ よりは高く、 Milner の $10 \mathrm{MHF}-6 \mathrm{MH}_{2} \mathrm{SO}_{4^{-}}$

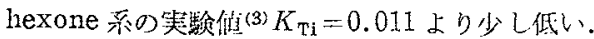

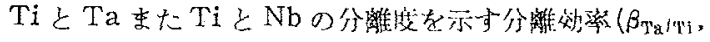

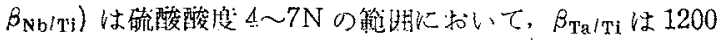
$\sim 1600, \beta_{\mathrm{Nb} / \mathrm{Ti}}$ は850 1100で闻者の良好方分離を示すが，

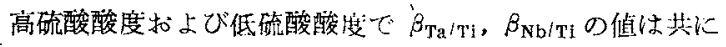

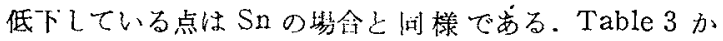

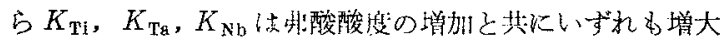

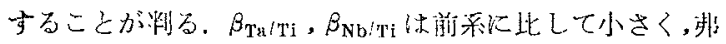

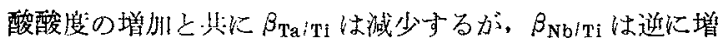

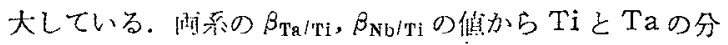
離の方が一般に $\mathrm{Ti}$ と $\mathrm{Nb}$ の分離より良好である。

\section{2. 実験 B：一Ta およびTiの溶解液をへキ ソンで抽出した場合のTiの举動}

本帮験の目的和よび奏䮖方法は前報しと问様であり， Hermann Starck Gosler 製の $\mathrm{Ta}_{2} \mathrm{O}_{5}$ を弗酸にしかした

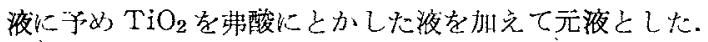

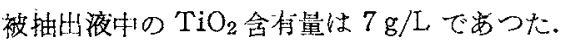

(1)弗酸酸度および酼酸酸度の Ti 抽出性に およばす影響

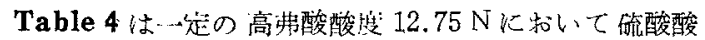

Table 4 Ti.extractability in $12.75 \mathrm{NHF}-$ $\mathrm{H}_{2} \mathrm{SO}_{4}$-Hexone system.

\begin{tabular}{c|c|c|c|c}
\hline $\begin{array}{c}\mathrm{H}_{2} \mathrm{SO}_{4} \\
\text { Nor- } \\
\text { mality }\end{array}$ & $\begin{array}{c}\% \text { Ta and } \\
\text { Nb } \\
\text { extracted }\end{array}$ & $\begin{array}{c}\% \text { TiO } \\
\text { extract }\end{array}$ & $\begin{array}{c}\mathrm{mg} \mathrm{TiO}_{2} \\
\text { in extract }\end{array}$ & $\begin{array}{l}\text { Distribu- } \\
\text { tion } \\
\text { coefficient } \\
K_{\mathrm{Ti}}\end{array}$ \\
\hline 11.35 & 91.40 & 0.275 & 5.86 & $4.37 \times 10^{-2}$ \\
7.08 & 90.00 & 0.075 & 1.59 & $1.15 \times 10^{-2}$ \\
4.25 & 87.14 & 0.062 & 1.26 & $9.10 \times 10^{-3}$ \\
1.42 & 78.30 & 0.040 & 0.74 & $5.33 \times 10^{-3}$ \\
\hline
\end{tabular}

度を变化し、水溶液量と等量のへキソンで 1 回抽出した場 合の, ヘキソン抽出物中の $\mathrm{TiO}_{2}$ 含有率, 含有最, 分配係 数などにおよ核す硫酸酸庭の影響を示している。硫酸酸度 の增加之共に Ti 含有率, 含有量, 叔よび分配係数は增加 に、硫酸酸度 $7 \mathrm{~N}$ 以上に拈いてはTi は著しく抽出される。

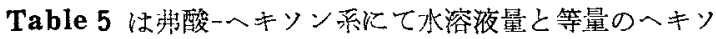
ンで抽出を行つた場合に批りる带酸酸度のへキンン1回抽

(2) J.M.Fletcher et al: Trans. Institute Min. and:Metallu., $65(1955 \sim 56), 487$.

(3) W.C.Milner et al: Analyst, 80 (1955), 380 ,

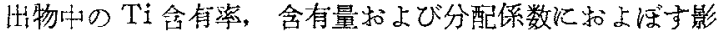
留を此較したものである．弗酸酸度の增加と共に Ti 含有

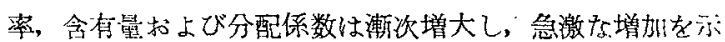
Table $5 \mathrm{Ti}$ extractability in HF-Hexone system.

\begin{tabular}{c|c|c|c|c}
\hline $\begin{array}{c}\mathrm{HF} \\
\begin{array}{c}\text { Nor- } \\
\text { mality }\end{array}\end{array}$ & $\begin{array}{l}\% \mathrm{~T} \text { Ta and } \\
\mathrm{Nb}\end{array}$ & $\begin{array}{c}\% \\
\text { extracted } \mathrm{TiO}_{2} \\
\text { in extract }\end{array}$ & $\begin{array}{c}\text { mg } \mathrm{TiO}_{2} \\
\text { in extract }\end{array}$ & $\begin{array}{l}\text { Distribu- } \\
\text { tion } \\
\text { coefficient } \\
K_{\mathrm{Ti}}\end{array}$ \\
\hline 21.2 & 68.75 & 0.119 & 1.98 & $1.43 \times 10^{-2}$ \\
15.9 & 65.91 & 0.071 & 1.12 & $8.05 \times 10^{-3}$ \\
10.6 & 63.21 & 0.031 & 0.47 & $3.40 \times 10^{-3}$ \\
7.95 & 61.40 & 0.022 & 0.33 & $2.33 \times 10^{-3}$ \\
\hline
\end{tabular}

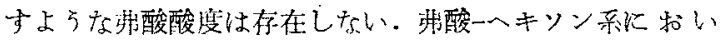
て, 非酸酸度 $12.75 \mathrm{~N}$ の $\mathrm{TiO}_{2}$ 含有率和上び分配係数は それを゙れ $0.052 \%, 5.28 \times 10^{-3}$ であり，12.75 N 弗酸一 梳酸一キソン系にて相当值を得るための硫酸酸度は，去れ ぞれ $3 \mathrm{~N}, 1.4 \mathrm{~N}$ である。硫酸酸度 $1.4 \mathrm{~N}$ 以下以和いては $12.75 \mathrm{~N}$ 弗酸一硫酸一一キンン委は $12.75 \mathrm{~N}$ 弗酸一へキンン

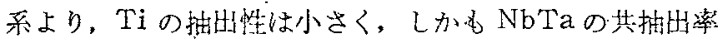
は10〜15\%大さという利点を有することになる。

（2）水溶液組成の種類および抽出回数の Ti抽 出性におよばす影響

Fig. 1 は弗酸酸度 $15.90 \mathrm{~N}$-硫酸酸度 $8.85 \mathrm{~N}$ ，沸酸酸度

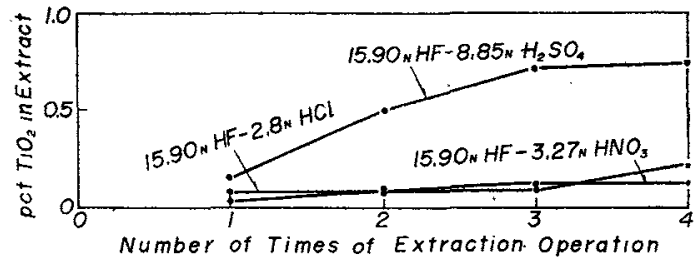

Fig. 1 Effect of number of times of extraction on $\% \mathrm{TiO}_{2}$ in extract.

$15.90 \mathrm{~N}$-硝酸酸度 $3.27 \mathrm{~N}$ ，および弗酸酸度。15.90 N-塩酸 酸度 $2.8 \mathrm{~N}$ なる我溶液を等量のへキソンで $1,2,3$ 牤よび A回抽出した場合に和ける全へキソン抽出物中の Ti含有

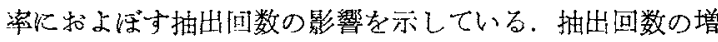

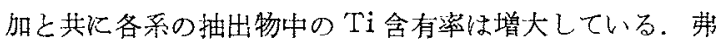
酸一硫酸系ではTi 含有率は抽出回数の增加と共に增大し て行くが，3回抽物とむ回抽出物はあまり差がない，弗

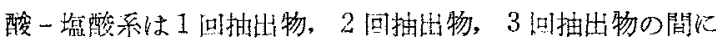

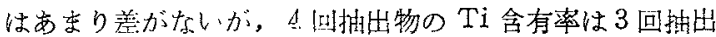

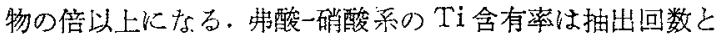
共にほぼ線的に増大している.Fig.2 は抽出回数と $\mathrm{TiO}_{2}$

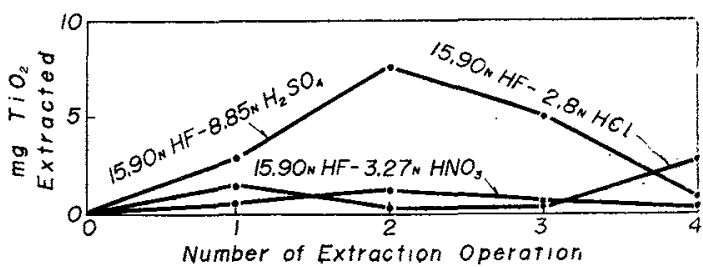

Fig.2 Effect of number of extraction on the extracted $\mathrm{TiO}_{2}$ weight.

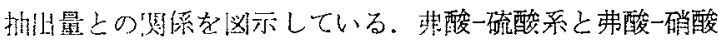
采はSnの等合と同稼に 2 回目の抽出量が最大となる山刑 


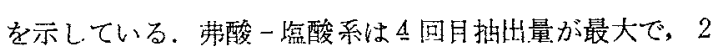

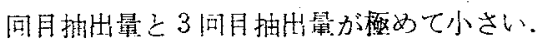

\section{3. 実験 $\mathrm{C}:$ 一タンタライト精鉱溶解液をへキ ソンで抽出した場合のTiの挙動}

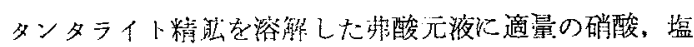
酸、硫酸、扣よび我などを加点て酸調整を们つた水溶液を 等量のヘキソンで抽出した，被抽出液中の $\mathrm{TiO}_{2}$ 含有量は

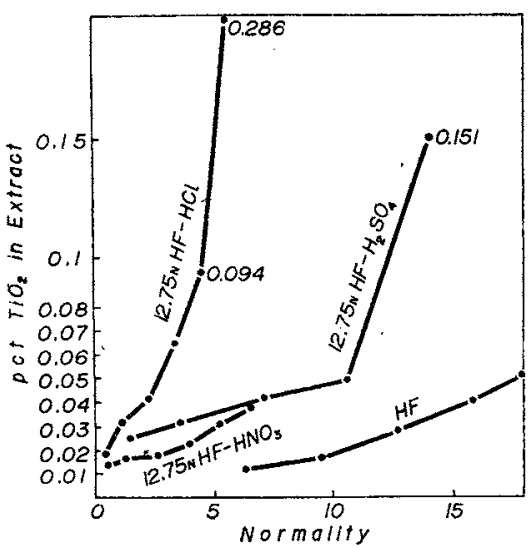

Fig. 3 Effect of acidity on $\% \mathrm{TiO}_{2}$ in extract.

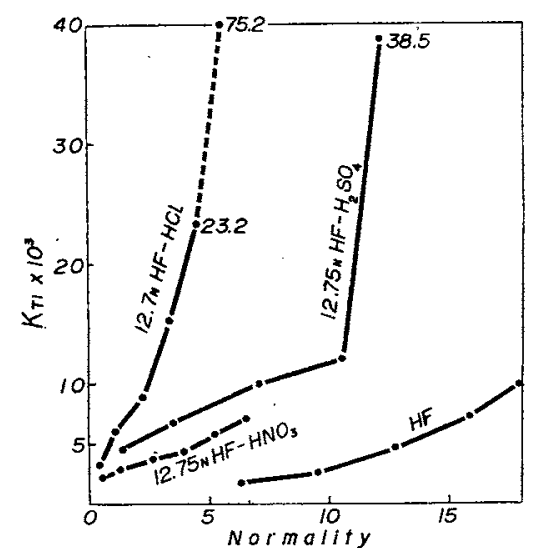

Fig. A Effect of acidity on Ti distribution coefficient.

Bの場合の

$\mathrm{TiO}_{2}$ 含有量

$7 \mathrm{~g} / \mathrm{L}$ に比 L て少底い。

酸度 $12.75 \mathrm{~N}$ るヘキンン
$5 \mathrm{~g} / \mathrm{L}$ で実娩

Fig.3 は弗酸

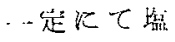

酸, 硫酸, 拈 よび硝酸酸度

を変化し九昜 合と弗酸のみ の系にて舞酸 酸度を变化し た場合比打 抽出物中の $\mathrm{TiO}_{2}$ 含有率 と各酸度との 関係索示して いる。また Fig.4 $\mathrm{Ti}$ 分配係数之各 酸度との関係 を示してい る. 塩酸, 硫 酸, 硝酸, 扰 よび弗酸酸度の增㧈と其にへキソン抽出物中の $\mathrm{TiO}_{2}$ 含有

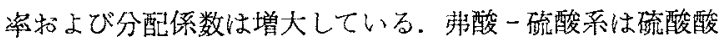
度10.6N から Ti 抽出性は著しく增大し, 砸酸一塩酸系は

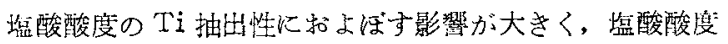
4.5N から Ti の抽出性は急激に增大している.

毁夋のみの系に扣いて弗酸酸度 $12.75 \mathrm{~N} の \mathrm{TiO}_{2}$ 含持率

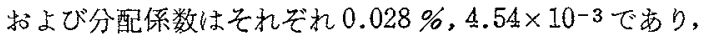
これらの值に相当する弗酸酸度 $12.75 \mathrm{~N}-$ 昿酸系の塩酸酸 度 $1 \mathrm{~N}, 0.8 \mathrm{~N}$; 硫酸酸度 $2.3 \mathrm{~N}, 1.5 \mathrm{~N}$; 硝酸酸度 $5 \mathrm{~N}$, $4.2 \mathrm{~N}$ である。これらの各鉣酸酸度以下ではへキンン抽出 物中の $\mathrm{Ti}$ 含有率括よび分配係数怯弗酸のみの系より秀れ， さらに NbTa 共抽出率の点で酸の文の系より優位であ ることはSnの場合と同様である．Fig.3,Fig.4から明ら かなように本実験で行つたような高弗酸酸度 $12.75 \mathrm{~N}$ に市

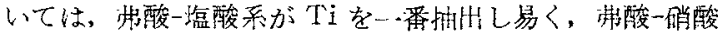

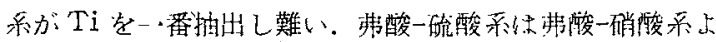
り Ti 抽性性が少し高いが大盖はならい。

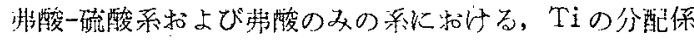
数を実験 A,B 拉よびCについて比較すると Table 6,Ta-

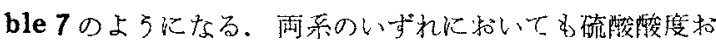

Table 6 Distribution coefficient of $\mathrm{T} i$ in 12.75 $\mathrm{N} \mathrm{HF}-\mathrm{H}_{2} \mathrm{SO}_{4}$-Hexone system.

\begin{tabular}{c|c|c|c}
\hline $\begin{array}{c}\mathrm{H}_{2} \mathrm{SO}_{4} \\
\text { Normality }\end{array}$ & \multicolumn{3}{|c}{ Experimental No. } \\
\hline & $\mathrm{A}(\mathrm{Ti} 7 \mathrm{~g} / \mathrm{L})$ & $\mathrm{B}(\mathrm{Ti} 7 \mathrm{~g} / \mathrm{L})$ & $\mathrm{C}(\mathrm{Ti} 5 \mathrm{~g} / \mathrm{L})$ \\
\hline 11.35 & $1.06 \times 10^{-1}$ & $4.37 \times 10^{-2}$ & $2.42 \times 10^{-2}$ \\
7.08 & $2.48 \times 10^{-2}$ & $1.15 \times 10^{-2}$ & $1.01 \times 10^{-2}$ \\
1.25 & $9.91 \times 10^{-3}$ & $9.10 \times 10^{-3}$ & $7.40 \times 10^{-3}$ \\
1.42 & $7.31 \times 10^{-3}$ & $5.33 \times 10^{-3}$ & $4.53 \times 10^{-3}$ \\
\hline
\end{tabular}

Table 7 Distribution coefficient of $\mathrm{Ti}$ in HF-Hexone system.

\begin{tabular}{c|c|c|c}
\hline \multirow{2}{*}{$\begin{array}{c}\text { HF } \\
\text { Normality }\end{array}$} & \multicolumn{3}{|c}{ Experimental No. } \\
\cline { 2 - 3 } & $\mathrm{A}(\mathrm{Ti} 7 \mathrm{~g} / \mathrm{L})$ & $\mathrm{B}(\mathrm{Ti} 7 \mathrm{~g} / \mathrm{L})$ & $\mathrm{C}(\mathrm{Ti} \mathrm{5g} / \mathrm{L})$ \\
\hline 21.2 & $2.03 \times 10^{-2}$ & $1.43 \times 10^{-2}$ & $1.39 \times 10^{-2}$ \\
15.9 & $1.00 \times 10^{-2}$ & $8.05 \times 10^{-3}$ & $7.24 \times 10^{-3}$ \\
10.6 & $4.60 \times 10^{-3}$ & $3.40 \times 10^{-3}$ & $3.20 \times 10^{-3}$ \\
7.95 & $3.00 \times 10^{-3}$ & $2.33 \times 10^{-3}$ & $2.10 \times 10^{-3}$ \\
\hline
\end{tabular}

よび州酸酸度の增大と其に $K_{\mathrm{T}}$ は堌大して扣り，各酸度に

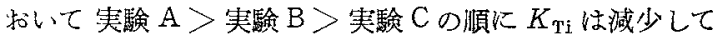

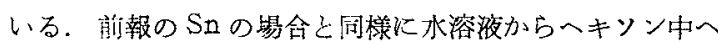
の Tiの抽出性他他の金属元素の存在によつて小さくなる ようである。

\section{IV. 紷 括}

(1) $\mathrm{Nb}$ ， Ta の液液抽出分離に使用される势酸一へキy ン系，弗酸一硫凌一ーキンン采について，Ti，Ta执よび Nb 個々の分配係数の測定值から Tiは $\mathrm{Nb}$ 特よび Ta の抽出 洔以分離出来ることが判り，タンタライト精鉱の抽崖実験 で磪めた。

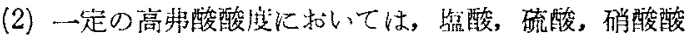
度の增加と其に，有機溶媒へキソンによつて抽出される抽 出物中の Ti 含有萃，含有舅および分配係数は增加する。

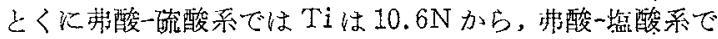
は4.5Nから急激に增加している。茀酸一硝彯系および弗 酸のみの菜は酸度の增加と其江徐々に增加し，急激な堌加 を示すような酸度は存在しない。

(3) 一定の高弗酸酸度 $12.75 \mathrm{~N}$ にて踹酸，硫酸，硝酸酸 度を变化させた実駼結果加ら，Ti の抽出性は弗酸一塩酸系 >弗酸一硫酸系>弗酸一硝酸系の順に減少する。

(4) 弗酸一塩酸系，弗酸一硫酸丞，弗酸一硝酸系の各系て は, 抽出回数の堌加之共に抽出物中の Ti含有率は堵加し， 抽出回数上 $\mathrm{Ti}$ 抽出量との関係から，柫酸一硫酸系拉よび 弗酸一硝酸系は，2回目の抽出量が最大壆となる山型を示 


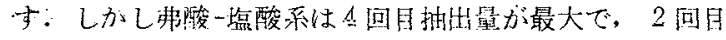
抽出留と 3 国目抽出量が板好て小さい。

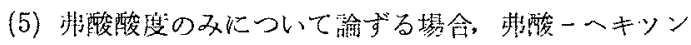

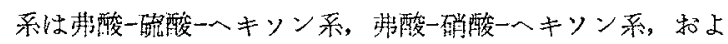

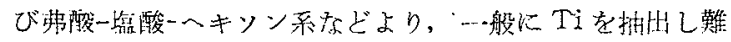

い.しかし一定の高弗酸酸度 $12.75 \mathrm{~N}$ に扎いては, 硫酸酸

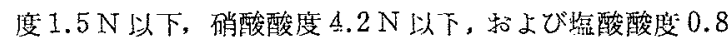
N以下の場合は，それぞれの拂酸一釷酸系のTi抽情性は

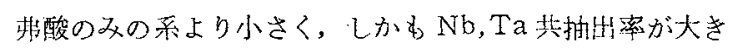
いという利点を有与る。 